\title{
Selection Progress for Resistance to Iris Yellow Spot in Onions
}

\author{
Neel Kamal ${ }^{1,3}$ \\ Seminis Vegetable Seeds (Monsanto Company), P.O. Box 653, Mesquite, NM \\ 88048 \\ Christopher S. Cramer ${ }^{2}$ \\ Department of Plant and Environmental Sciences, New Mexico State \\ University, Box 30003, MSC 3Q, Las Cruces, NM 88003-8003
}

Additional index words. Allium cepa, Iris yellow spot virus, Thrips tabaci, ELISA

\begin{abstract}
Onion thrips (Thrips tabaci Lindeman)-vectored Iris yellow spot virus (IYSV) causes the disease Iris yellow spot (IYS), which is a major threat to the sustainability of onion production worldwide. An increase in thrips resistance to various insecticides, high costs, and the limited efficacy of insecticides under hot and drier conditions found in various onion-growing regions restrict grower's options for effective control of thrips and spread of IYSV. Because cultivars resistant to thrips and IYS are lacking, this study was undertaken to measure selection progress for IYS resistance after one selection cycle. In 2009, selections were performed on previously evaluated New Mexico State University (NMSU) breeding lines that showed some reduced IYS disease symptoms, and the selected plants self-pollinated the following year. In 2011 and 2012, plants from the original and selected populations along with a susceptible check, 'Rumba', were evaluated under field conditions when onion thrips and IYSV were present. Plants were rated for IYS disease severity and the number of thrips per plant was recorded three times during the study in each year. First-generation material, NMSU 10-776, NMSU 10782, NMSU 10-785, NMSU 10-807, and NMSU 10-813, had fewer thrips number per plant, lower disease severity, and disease incidence than their original breeding lines on at least one or two rating times in both years. Some first-generation breeding lines performed better with a lower thrips number and disease severity than their original population in 1 year or the other. Most entries exhibited fewer thrips, lower IYS disease severity, and less incidence than the susceptible check 'Rumba' at most rating times. Overall, some progress was observed in this first-generation material for reduced IYS disease symptom expression when compared with their original populations.
\end{abstract}

Iris yellow spot virus (family Bunyaviridae, genus Tospovirus) was first reported as Tomato spotted wilt virus in southern Brazil in 1981 affecting onion scapes (de Avila et al., 1981 cited in Gent et al., 2006) but later confirmed as a new tospovirus after several research studies on onion bulb and seed crops (Cortês et al., 1998; Gent et al., 2006). First report of IYS disease on bulb onions was confirmed in the southwest Idaho and Oregon region in the United States (Hall et al., 1993). Later, IYS disease has been confirmed in almost all major

Received for publication 2 Mar. 2018. Accepted for publication 17 May 2018.

This research was funded in part by the USDA-NIFA Specialty Crop Research Initiative grant number 2008-51180-04875, the New Mexico Agricultural Experiment Station, and the New Mexico Dry Onion Commission.

Selection progress for resistance to Iris yellow spot in onions.

We wish to thank Monsanto Company for the tuition support and Rick Jones, Onion Breeder at Monsanto Company for the support during the completion of this research.

${ }^{1}$ Research Associate.

${ }^{2}$ Professor of Horticulture.

${ }^{3}$ Corresponding author. E-mail: neel.kamal@ monsanto.com. number of generations can intensify the spread of IYS due to the limited control of thrips even by the use of various insecticides more frequently (Cramer et al., 2014). In addition, an increase in thrips resistance to various insecticides, such as pyrethroids and organophosphates, reduces grower's chemical options to control onion thrips and IYS (Cramer et al., 2014; Diaz-Montano et al., 2011; Gent et al., 2006; Mohseni-Moghadam et al., 2011).

IYSV-infected onion plants generally exhibit small necrotic lesions at first that later join together and decrease leaf photosynthetic area, which affects bulb yield and decreases the number of larger sized bulbs (Cramer et al., 2014; du Toit et al., 2004a; Gent et al., 2004; Schwartz et al., 2002; Shock et al., 2008). A significant decrease in the number of bulbs of the jumbo and colossal market classes due to the presence of IYS in the field has been observed (du Toit et al., 2004b). For onion seed crops, an increase in the number and size of lesions due to IYS often results in the girdling of the seed scapes and lodging, which can reduce seed yields (du Toit et al., 2004a; Gent et al., 2004). Crowe and Pappu (2005) reported $30 \%$ to $100 \%$ symptomatic and $15 \%$ to $95 \%$ lodged plants in an onion field. In the western United States, an IYS epidemic in an onion bulb production field can result in a $10 \%$ to $15 \%$ economic loss, excluding the additional cost of increased pesticide applications (\$7.5-\$12.5 million dollars) (W1008: Biology and Management of IYSV and thrips in onions, 2011; Gent et al., 2006), whereas complete loss of onion bulb crop in Brazil was reported by Pozzer et al. (1999).

Developing or finding onion germplasm that exhibits reduced thrips feeding injury, resistance or both to onion thrips can be important in developing IYS-resistant cultivars (Al-dosari, 1995; Mahaffey, 2006). Mahaffey (2006) reported cultivar differences in thrips-feeding injury and yield at similar thrips infestations. Differences in leaf epicuticular waxes among onion cultivars appear to affect thrips preference and feeding injury (Coudriet et al., 1979; Damon et al., 2014; Jones et al., 1934; Molenaar, 1984). In addition, glossy foliage (plant leaves that accumulate less epicuticular wax) with a lighter green color tends to inhibit thrips growth (Molenaar, 1984) along with a reduction in egg hatching (Rosingh, 1980 cited in Gent et al., 2006). Diaz-Montano et al. (2012) found that bluish foliage cultivars Yankee and Nebula exhibited a greater number of thrips larvae as compared with cultivars with greenish foliage. Similar results of greater thrips attraction to blue hues as compared with green hues were reported in other studies [(Czencz, 1987; Kirk, 1984; and Lu, 1990) cited in Gent et al. (2006)]. Cramer et al. (2014) suggested that foliage traits, such as leaf color and epicuticular wax, are not always the main reasons behind the differences in thrips number among various cultivars. In a field evaluation of various cultivars, leaf color, and amount of leaf epicuticular 
wax were not consistent factors in determining the number of thrips per plant (Cramer et al., 2017).

Several studies reported differences for thrips number, thrips-feeding injury, and IYS for screened onion germplasm but no single onion cultivar has been found to be resistant or immune to IYS (Boateng et al., 2014; Cramer et al., 2014; du Toit et al., 2004b; Gent et al., 2004, 2006; Mohseni-Moghadam et al., 2011; Multani et al., 2009; Shock et al., 2008; Singh, 2013). Creamer et al. (2004) reported differences among three cultivars for IYS incidence. Significant differences for IYS susceptibility and severity were also observed for 46 onion cultivars (du Toit et al., 2004b). Schwartz et al. (2005) reported $13 \%$ to $100 \%$ IYS incidence among onion cultivars in a 2-year study. Diaz-Montano et al. (2010) also found differences between entries for their IYS resistance. MohseniMoghadam et al. (2011) screened 13 winter-sown onion entries and found NMSU 05-33-1 more disease resistant whereas 'Denali' and 'Gelma' exhibited higher susceptibility as compared with other entries. In a study conducted by Cramer et al. (2012), plants of 'Cometa' and NMSU 05-35-1 showed fewer disease symptoms along with lower levels of IYSV as compared with the other entries in the study. Singh (2013) reported that entries NMSU 10-575-1, 10$577-1$, and 10-582-1 showed less disease severity than their original populations from which these entries were selected. PI accessions 239633 and 546192 showed fewer IYS symptoms than most accessions evaluated (Cramer et al., 2014). In another study, Cramer et al. (2017) found plants of NMSU 09-58 exhibited less disease symptoms than other entries when plants were rated early in the season.

The aforementioned studies suggest that variation exists in onion germplasm for resistance to onion thrips and IYS. By performing selections on this germplasm, it may be possible to enhance the level of IYS resistance. This study was undertaken to determine if selected onion populations differ in their resistance levels to onion thrips and exhibit reduced IYS symptom expression after a single selection cycle when compared with their original breeding lines from the NMSU onion-breeding program.

\section{Materials and Methods}

In 2009, individual onion bulbs that exhibited reduced IYS symptoms and less thrips-feeding damage were selected from different NMSU onion-breeding lines. These lines were chosen based on historical knowledge of reduced disease severity and thrips number from a previous study on IYS (Cramer et al., 2014, 2017). In addition, the health and maturity stage of plants were key determinants when making selections. In general, plants that are close to maturing tend to be more IYS susceptible than immature plants (Cramer et al., 2014) and differentiating between leaf senescence and IYS symptoms can be difficult (Multani et al., 2009). Selfpollinated seeds were produced in 2010 from these individually selected plants. Additional information on the germplasm origin of the NMSU lines used in this study has been published in other research articles by Cramer et al. in 2014 and 2017.

Twenty-six entries that comprised 17 selected lines, eight originating populations, and a susceptible check cultivar, Rumba (Nunhems USA, Parma, ID), were evaluated under field conditions in 2011 and 2012. Each year, the field experiment was conducted at the Leyendecker Plant Science Research Center (lat. $32^{\circ} 11^{\prime} 52.2384^{\prime \prime} \mathrm{N}$, long. $\left.106^{\circ} 44^{\prime} 33.252^{\prime \prime} \mathrm{W}\right)$ Las Cruces, NM, using a randomized complete block design with three replications for each entry. Entries were hand sown in the field on 23 Feb. 2011 and 22 Feb. 2012. The length and width of the plots were 3 and $0.5 \mathrm{~m}$, respectively with $0.6 \mathrm{~m}$ alleys between two adjacent plots on the same planting bed. Two rows on each bed were overplanted at the rate of $1.5 \mathrm{~g}$ onion seed per plot. To ensure proper spacing, seedlings were thinned to $10 \mathrm{~cm}$ spacing between two adjacent plants within the row. The thinning of the plants was conducted in the second week of May in 2011. During 2012, thinning was performed in the last week of May to the first week of June because of the slower growth of plants in the second year of study.

To ensure the presence of viruliferous onion thrips in the field and to provide a continuous supply of leaf matter for onion thrips to feed on and for them to acquire and spread IYSV, a field design similar to Cramer et al. (2014) and Singh (2013) was followed in both years. Bulbs from previous year's IYS disease evaluation that showed extreme disease symptoms, were saved due to the likely presence of IYSV-infected thrips within the dry scales of these bulbs. These bulbs were planted on the first and last bed of the study along with the front and back borders in Oct. 2010 and Oct. 2011. After every two rows of the test plots, IYS disease-susceptible cultivar NuMex Dulce from the NMSU breeding program was sown in Oct. 2010 and Oct. 2011 to act as disease-spreader rows. Onions were grown in the field using standard cultural practices recommended by Walker et al. (2009) for onion production in southern New Mexico. No insecticides were sprayed to maintain the thrips population in the field. Weed control was carried out manually and chemically to control weeds at various growth stages.

Plots were rated for leaf color on a scale of 1 to 4 , where $1=$ light green foliage [Hex color-7DC896 (Kamal, 2016)], 2 = dark green (194B19), 3 = blue green (4B967D), and $4=$ blue (4B7D96) at 17 weeks after planting (WAP). At the same time, plots were rated for leaf epicuticular waxiness on a scale of 1 to 4 , where 1 = glossy, 2 = semi glossy, 3 = light wax, and $4=$ waxy (Cramer et al., 2014). Data on leaf color and wax were recorded to see if differences in these traits relate to any observed differences in thrips number as reported in many studies (Cramer et al., 2014, 2017; Damon et al., 2014; DiazMontano et al., 2012). Thrips number (both adult and larvae) were recorded from 10 arbitrarily selected plants in the center of each plot at 13, 17, and 21 WAP in 2011 and at 17,21 , and $25 \mathrm{WAP}$ in 2012 . Thrips counts were delayed in 2012 planting by 4 weeks as plants were not at the same physiological growth stage (number of leaves) at 13 WAP in 2012 as compared with 2011 . IYS severity ratings were conducted at 17,21 , and 23 WAP in 2011 and at 17, 21, and 25 WAP in 2012. For measuring symptom severity, 10 arbitrarily selected plants from each plot at each rating time were rated for IYS severity on a scale of 0 to 4 , where $0=$ no symptoms; $1=1-2$ small lesions per leaf; $2=>2$ medium sized; $3=$ lesions coalescing on more than $25 \%$ of the leaf; and $4=$ more than $50 \%$ leaf death (Cramer et al., 2014). All the ratings and counts were carried out relatively at the same time of the day on the day of counts and ratings to mitigate the influence of daytime on leaf wax, color, and thrips number. Disease incidence in each plot was calculated as the ratio of plants that showed IYS symptoms to the total number of arbitrarily selected plants rated for disease severity in that plot. Bulbs from a plot were harvested when plant tops of $\approx 80 \%$ of the plants in that plot had lodged or the plant neck tissue had softened or there was severe necrosis of leaf tissue due to the presence of IYS. The date of harvest was recorded for each plot. Plots in which plants did not produce a bulb or the plants did not mature by the end of harvest season (midSeptember) were not harvested. In addition, plants with less thrips-feeding damage and reduced IYS disease at maturity were selected within plots and saved separately for future studies.

Leaf tissue samples of 5-7 cm, that may or may not have had symptomatic tissue, were collected from the leaf tips of the 10 arbitrarily selected plants from each plot at each disease severity rating to confirm the presence of IYSV. Leaf tissue samples from each plot were put in separate plastic bags and stored in an ice chest before transfer and storage at $-4{ }^{\circ} \mathrm{C}$. Enzyme-linked immunosorbent assay (ELISA) using the method developed by Copeland (1998) but with minor changes carried out by MohseniMoghadam et al. (2011) and Singh (2013) was used to detect the presence of IYSV. About $0.5 \mathrm{~cm}$ of leaf tissue from the 10 plants of each plot was placed in a 2-mL Eppendorf microcentrifuge tube (Eppendorf North America, Hauppauge, NY) without deliberately checking for the presence of IYS symptoms. Several leaf tissue samples with the highest and lowest field IYS severity ratings were used to develop positive and negative controls in each year for ELISA plate readings. By using ELISA plate reader at $405 \mathrm{~nm}$ (Biotron Diagnostics, Inc., Hemet, CA), optical density (OD) values of plates were measured to obtain the relative absorbance values. Plant samples were considered positive when their ELISA OD values were 
higher than its respective negative control plus three times its standard deviation.

Data from both years were analyzed separately because of differences in various environmental factors, rating dates, and number of entries tested in each year. Data were analyzed by using the Proc General Linear Models statement in SAS (SAS 9.0; SAS Institute Inc., Cary, NC) to determine if there are differences among entries for leaf color, leaf wax, thrips number, IYS severity ratings, and incidence. The mean of each character and ratings for each entry were calculated by using the "Proc Means" command in SAS. The "Pdiff" command in SAS was used to test for mean differences for leaf color, leaf wax, thrips population, severity rating, and incidence on a particular date between the selected breeding lines and their original populations at probability level of less than 5\%. Original and selected breeding lines were also compared separately with the susceptible check, 'Rumba', using the "Pdiff" command for all traits except for OD at a probability level of less than $5 \%$. The "Proc Means" statement in SAS was used to calculate the average ELISA OD values for each entry by averaging more than three replications. Mean separation tests were not performed for OD values because of their semi-quantitative nature and their relativeness to the blank control used in the test. Data from entries with less than two replications were not included and plots with less than five plants were discarded earlier in the season.

\section{Results and Discussion}

The comparison of selected lines with their originating lines did not show any differences for foliage color at 17 WAP (data not shown). In addition, few differences were detected between selected entries and their original entries for leaf wax ratings and maturity in both years (data not shown). These results were not unexpected because plants were not selected for leaf color, leaf wax amount, or maturity time. In 2012, onion plants did not grow quickly and were smaller in size at the first thrips count at 13 WAP as compared with 2011. To ensure that plants were at the right physiological stage as that of plants grown in 2011, the first count of thrips number per plant was delayed by 4 weeks in 2012. In 2011 and 2012, selected lines differed in only a few instances for thrips number per plant from their respective originating lines when thrips were counted at different times (Table 1).

Early in the growing season of both years, the selected and their original breeding lines were similar for their number of thrips per plant (Table 1). No differences in foliage color and amount of wax ratings were observed between plants of these two lines. In 2011, plants of the selected lines NMSU 10775 (5.1), 10-776 (9.3), and 10-777 (7.7) had fewer thrips than plants of their original population NMSU 07-30-2 (20.7) at 17 WAP (Table 1). At the other two thrips counts, no differences were observed between these selected and their original lines. In 2012, differences were not observed for thrips number between the aforementioned selected lines and their original line, and this lack of difference might have been caused by a lack of thrips buildup on plants of 07-30-2. At the first and second thrips count, plants of NMSU 10-807 exhibited a similar number of thrips as plants from its originator line, NMSU 07-53-1; however, plants of 10-807 had less thrips buildup from the second to the third count in 2011 and 2012. These aforementioned results indicate differences between selected and original lines for the buildup of thrips populations during plant growth that could result in a delay in or lesser leaf tissue damage due to fewer thrips feeding on a plant at one time or another and may contribute toward higher yields. For remainder of comparisons in 2011, no differences were observed between the selected and original entries with regard to number of thrips.

In 2012, fewer thrips per plant were observed on selections NMSU 10-804 (3.7) and $10-813(2.1)$ than their original line NMSU 07-53-1 (13.8) at 21 WAP. In addition, plants of NMSU 10-813 (10.2) had less thrips buildup from 21 to 25 WAP than plants of NMSU 07-53-1 (23.1). In addition, plants of NMSU 10-795 (19.1) exhibited fewer thrips than plants of its original population NMSU 07-35-1 (32.3) at 25 WAP. No differences were observed for leaf color, leaf waxiness, and plant maturity between the aforementioned selected lines and the original breeding lines (data not shown), making foliage characteristics and maturity unlikely explanations for the lower number of thrips on these selected lines. One likely reason for the nonpreference thrips feeding could be that plants of these selected lines still had not much leaf matter and were growing slower as compared with other entries and this difference might have made these plants less attractive. Unfortunately, plant height was not measured in the study that could have accounted for plant size differences. However, in future works it would be ideal to express thrips number as per leaf rather than per plant because it would be expected a plant with more leaves to have more thrips than a plant with fewer leaves. These results suggest that it might be possible to improve breeding material for thrips resistance independent of leaf characteristics (Singh, 2013). Cramer et al. (2017) also reported that lighter green color leaves and a lower amount of leaf epicuticular wax were not consistent predictors for the number of thrips on some plants.

In general, plants did not exhibit IYS symptoms in the test plots until early June in 2011 and by mid to late June in 2012. Typical symptoms such as diamond-shaped, chlorotic lesions were present on the plants in the border and spreader rows early in the seasons in both years and these symptoms were confirmed to be from IYSV with ELISA. In 2011, IYS severity ranged from
0.0 to 0.3 at $17 \mathrm{WAP}, 0.2$ to 0.7 at $21 \mathrm{WAP}$, and 0.5 to 1.3 at $23 \mathrm{WAP}$, whereas disease incidence ranged from $0.0 \%$ to $30.0 \%$ at 17 WAP, $20.0 \%$ to $66.7 \%$ at $21 \mathrm{WAP}$, and $46.7 \%$ to $96.7 \%$ at 23 WAP (Table 1 ). In 2012, IYS symptom expression increased dramatically over time with mean severity ratings of $0.3,1.5$, and 2.5 at 17,21 , and 25 WAP, respectively (Table 1). One possible explanation for the higher IYS severity could be warmer temperatures in 2012 (New Mexico Climate Center, 2012) that might have enhanced symptom expression. In addition, mean disease incidence was higher in 2012 than in 2011 at all times. ELISA was performed as an indirect measure of virus titer to confirm if plants with or without IYS disease symptoms had IYSV. Plants of all entries tested positive for IYSV in both years except for NMSU 10-785 and 07-56-2, which were determined to be negative for IYSV presence at 17 WAP in 2012 (Table 1).

At 17 WAP in 2011, plants of NMSU 10$775,10-776$, and 10-777 exhibited a lower disease severity $(0.03)$ and incidence $(3.3 \%)$ than plants of their original population NMSU $07-30-2(0.3 \%$ and $30.0 \%$, respectively) (Table 1). Plants of these entries tested positive for IYSV at 17 WAP. NMSU 10-776 matured later than NMSU $07-30-2$ by 3 weeks (data not shown), which could mean that plants were at a different physiological stage and might have contributed for the delayed symptom expression and lower disease incidence of NMSU 10-776. Because, it is likely that plants which are actively growing might be more tolerant to stress and do not exhibit symptoms even when IYSV is present in the plants (Cramer et al., 2014). However, the other two selected lines from NMSU 07-30-2 were not different in terms of maturity. Another possible explanation could be that after being infected with fewer viruliferous thrips due to slower thrips buildup from 13 to 17 weeks on plants of the selected lines than on plants of NMSU 07-30-2; plants of selected lines had less time for IYSV buildup and symptom expression.

At the other rating times in 2011, IYS severity and incidence of these selected breeding lines were not different from their original line (Table 1). The plants of NMSU 10-775 and 10-777 were not different from the plants of NMSU 07-30-2 for disease severity and incidence at any rating time in 2012; however, NMSU 10-776 exhibited a lower severity at 25 WAP and incidence at 21 and 25 WAP (Table 1). Differences observed between years for disease severity and incidence could be due to variation in temperatures, plant health, fertility, irrigation, rainfall, or field locations, which can affect thrips number as well as disease symptom expression.

At 21 WAP in 2011, plants of selection NMSU 10-782 exhibited a reduced IYS symptom expression $(0.2)$ and a lower incidence $(23.3 \%)$ from plants of its originator NMSU 07-32-1 (0.7, 63.3\%, respectively) and 'Rumba' $(0.7,60.0 \%$, respectively) (Table 1). A likely reason for the higher 
Table 1. Mean values and comparisons of selected lines with originating lines and 'Rumba' for number of onion thrips per plant, Iris yellow spot (IYS) disease severity rating, IYS disease incidence and enzyme-linked immunosorbent assay (ELISA) optical density (OD) SD values relative to the healthy control measured at various times throughout the growing seasons during the 2011 and 2012 at the Leyendecker Plant Science Research Center in Las Cruces, NM.

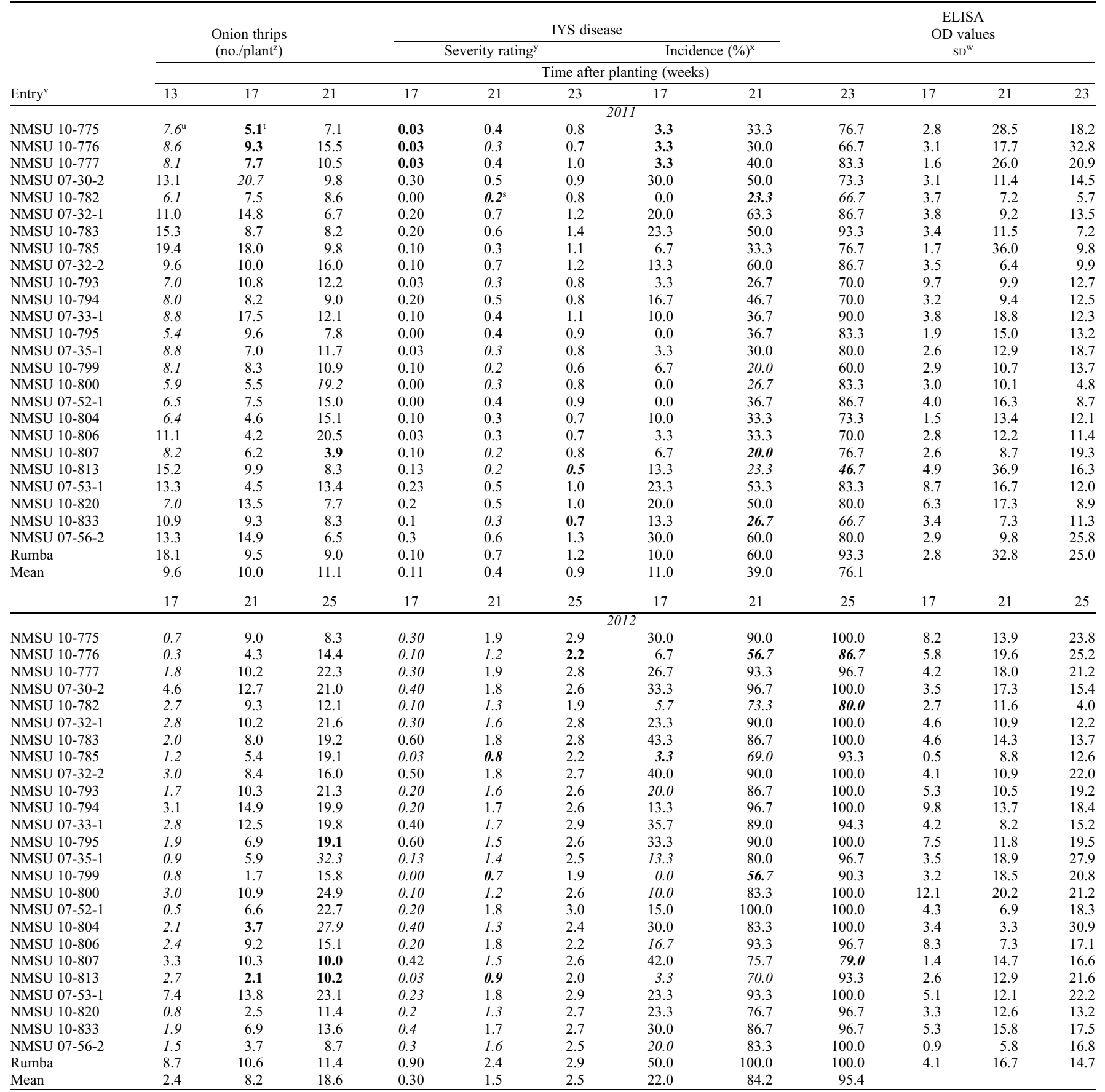

${ }^{\mathrm{z}}$ The number of thrips (juveniles and adults) per plant were counted from 10 plants arbitrarily selected in the center of each plot.

${ }^{\mathrm{y}}$ Ten plants per plot were rated individually for IYS severity on a scale of 0 to 4 , where $0=$ no symptoms, $1=1$ to two small lesions per leaf, $2=>2$ medium-sized lesions per leaf, 3 = lesions coalescing on more than $25 \%$ of the leaf, and $4=$ more than $50 \%$ leaf death.

${ }^{\mathrm{x}}$ Percentage of plants showing IYS disease symptoms were calculated based on 10 plants per plot.

${ }^{\mathrm{w}}$ Tissue samples were randomly bulked from 10 plants per plot and were analyzed using ELISA to obtain the OD values at $405 \mathrm{~nm}$. Values represent how many times the OD value for a particular entry is greater than its corresponding healthy control plus three SD of the healthy control. Based on this calculation, values greater than one would be considered positive for IYSV.

${ }^{v}$ Entries were tested in three blocks with one replication per block. Plots were $3 \mathrm{~m}$ in length and consisted of two equally spaced rows per plot. NMSU 10-775, 10776, and 10-777 came from NMSU 07-30-2; NMSU 10-782 came from NMSU 07-32-1; NMSU 10-783 and 10-785 came from NMSU 07-32-2; NMSU 10-793 and 10-794 came from NMSU 07-33-1; NMSU 10-795 came from NMSU 07-35-1; NMSU 10-799 and 10-800 came from NMSU 07-52-1; NMSU 10-804, 10806, 10-807, and 10-813 came from NMSU 07-53-1; NMSU 10-820 and 10-833 came from NMSU 07-56-2. 'Rumba' was included as susceptible check to thrips and IYS.

"Italics represents that entry mean was significantly different from the susceptible check 'Rumba', at $P \leq 0.05$.

tEntry means highlighted in bold represent that selected lines were significantly different from the mean value of its original line at $P \leq 0.05$.

${ }^{\mathrm{s}}$ Bold italics represent selected lines were significantly different from both its originating lines and 'Rumba' at $P \leq 0.05$.

NMSU = New Mexico State University. 
disease severity and incidence of 'Rumba' plants could be higher number of thrips on plants of 'Rumba' early in the season as compared with plants of NMSU 10-782. Similarly, plants of NMSU 10-782 exhibited a lower severity and incidence than plants of 'Rumba' at 17 and 21 WAP in 2012 (Table 1). Early in the growing season, plants of NMSU 10-782 (2.7) were infested with fewer thrips than plants of 'Rumba' (8.7) that could have contributed to the reduced symptom expression for plants of NMSU 10-782 (Table 1). This difference could be as a result of foliage differences as plants of 'Rumba' exhibited bluish green foliage whereas plants of NMSU 10-782 exhibited light green foliage (data not shown).

At 17 WAP in 2011, plants of NMSU 10782 rated for IYS severity did not show symptoms but still tested positive for IYSV (Table 1). A likely reason for the presence of IYSV in plants of NMSU 10-782 could be that leaf samples were arbitrarily collected from the plants within the plots and not specifically from the same plants that were rated for severity. A leaf sample with IYS disease symptoms might have been selected and later bulked with other leaf samples before testing for the presence of IYSV with ELISA. Alternatively, these plants could be asymptomatic and still have IYSV as reported by others (Diaz-Montano et al., 2010; Gent et al., 2004; Mohseni-Moghadam et al., 2011). NMSU 10-782 and 07-32-1 were not different for severity at 17 and 23 WAP in 2011 and at any of the rating times in 2012, whereas NMSU 10-782 had a lower disease incidence from NMSU 07-32-1 at 25 WAP in 2012 (Table 1).

At the last rating time in 2011, plants of NMSU 10-813 exhibited reduced symptom expression than plants of its original line NMSU $07-53-1$ and $37 \%$ fewer plants exhibited disease symptoms for NMSU 10813 (Table 1). At the first and second ratings, differences for disease severity between these two lines were not detected and this lack of difference might be due to slow disease progression. One possible explanation for a lower disease severity and incidence in the selected lines as compared with their original lines when other traits were not different could be the ability of plants in the selected lines to delay symptom expression. For example, plants of NMSU 10-813 (0.9) exhibited a reduced severity at the second rating in 2012 when compared with plants of NMSU 07-53-1 (1.8). At the same time, plants of NMSU 10-813 exhibited a slower buildup of thrips number per plant from 17 to 21 WAP as compared with plants of NMSU 07-53-1, which could partially explain the lower disease severity at 21 WAP (Table 1). Plants of both lines tested positive for IYSV with ELISA in 2011 and 2012. As explained earlier, IYS disease spread more readily in 2012 due to conducive environmental conditions (high temperatures, dry weather etc.), which may have made it more difficult to detect differences between comparisons by the third rating as most of the entries exhibited disease symptoms.
For other comparisons of entries evaluated in 2012, plants of selections NMSU 10785 (0.8) and NMSU 10-799 (0.7) exhibited reduced symptom expression compared with plants of their original breeding lines NMSU 07-32-2 (1.8) and NMSU 07-52-1 (1.8), respectively, as well as plants of 'Rumba' (2.4) at 21 WAP (Table 1). At 17 WAP, NMSU 10785 had fewer plants (3.3\%) with IYS symptoms than its original line NMSU 07-32-2 $(40.0 \%)$. In addition, leaf samples of NMSU $10-785$ tested as negative for IYSV at 17 WAP (Table 1). At 21 WAP, $57 \%$ of the plants of NMSU 10-799 exhibited disease symptoms in contrast to all of the plants of its original line NMSU 07-52-1. As no differences were observed for foliage characteristics, maturity (data not shown), and thrips number (Table 1) between plants of NMSU $10-785$ and $07-32-2$ as well as between plants of NMSU 10-799 and 07-52-1, one possible explanation for the lower disease severity and incidence early in the season could be that plants of NMSU 10-785 and 10-799 were still not actively growing yet which made them unattractive to thrips. Another possible explanation may be the ability of plants of NMSU 10-785 and 10-799 to delay symptom expression due to less plant stress or these plants might have an inherent resistance to symptom development.

IYS severity and incidence were not different for the previously mentioned comparisons later in the season. One reason for this lack of difference might be an increase in IYS symptom expression later in the season due to conducive environmental conditions, such as temperature, humidity, heat, and light intensity. The other possibility could be that plants were rated 2 weeks later in 2012 at 25 WAP (mid-August) and this date might be closer to plant maturity; therefore, plants could have been more susceptible and showed higher IYS severity. Higher severity close to maturity or at later rating dates has been reported previously (Cramer et al., 2014; Multani et al., 2009; Singh, 2013).

Entries such as, NMSU 10-807 had fewer number of plants with IYS symptoms than its original line NMSU 07-53-1 at 21 WAP in 2011 and 25 WAP in 2012, respectively (Table 1). A likely explanation could be that plants of NMSU 10-807 had fewer thrips than plants of NMSU 07-53-1 at the last thrips count in both years. However, differences in thrips number between the original and selected population did not result in differences for disease severity. One interpretation from these results could be that NMSU 10-807 might have had more severe symptoms on a fewer plants whereas NMSU 07-53-1 may have had a greater number of plants with a lower disease severity because disease incidence was based on the percentage of plants showing IYS symptoms from a plot.

Among the several plant selections made of the onion breeding lines from NMSU for improving the level of IYS resistance, thrips feeding or both, only a few showed some degree of enhancement toward fewer thrips per plant and delayed or reduced symptom expression. In addition, all of the selections from NMSU 07-33-1 did not show any differences for any of the measured traits in both years (Table 1). A number of factors might be responsible for the lack of differences for reduced IYS and fewer thrips. For IYS, symptom expression depends on the presence of IYSV and the vector (onion thrips) in the field, favorable environmental conditions (such as heat, temperature, light, and humidity), and many others, which can induce stress on plants and result in symptom expression (Cramer et al., 2014). Under unstressed conditions, a plant may not show IYS disease symptoms even when the virus and vector are present. In addition, a plant's inherent ability to tolerate plant stress (Cramer et al., 2014) can affect the ability to detect differences for IYS between different germplasms. Selection pressure and field design used in this study could have been too severe and reduced the ability to detect differences for IYS severity and higher thrips population in the field.

Because bulbs carrying viruliferous thrips from the previous year's study were planted before seeding of test plots and then higher thrips populations were maintained by not spraying insecticides, these two factors could have resulted in a highly stressful condition for plants. The original NMSU breeding lines on which selections were performed in 2009 had also shown more resistance to IYS in past studies (MohseniMoghadam et al., 2011); therefore, limited variability for reduced IYS symptom expressions for the original and selected populations could have been another reason for not detecting many differences. The other possibility could be that some of the selections were just escapes and did not have reduced or delayed symptom expression at the time of selection. Yearly differences for thrips number and growth of plants, single location, and one selection cycle can also be other factors affected the ability to detect differences.

\section{Conclusion}

Overall, no differences were observed for foliage characteristics and maturity for most of the comparisons between selected and original lines. As plants were selected from the original NMSU breeding lines for reduced IYS symptoms and lesser thrips feeding damage, and not on the basis for leaf color or leaf wax or maturity, the lack of differences in leaf color, leaf wax, and maturity between original and selected lines were not surprising. Plants of the selected lines NMSU 10-776, 10-782, 10-785, 10-807, and 10-813 had fewer thrips, and lower disease severity and incidence on at least one or two rating times in both years than plants of their original breeding line. A decrease in thrips number may eliminate one or several insecticidal applications for the control of thrips, reduce leaf damage, and reduce IYSV spread. In addition, a lower disease severity and incidence can increase bulb yield the 
number of bulbs of larger size, or both, and generate higher returns for growers. Because no insecticidal spray was applied on plants to control thrips number, entries that showed lower thrips number and IYS severity and incidence in this study may likely perform better when plants are grown under actual field conditions.

Entries, such as, NMSU 10-775, 10-777, $10-782,10-785$, and 10-833 performed better in 2011, whereas NMSU 10-799 and 10-804 performed better in 2012 from their original lines for lower thrips number and IYS severity and incidence at one or two rating times. A delay in symptom expression could be advantageous for overall higher yield and obtaining a higher number of bulbs in the larger size market classes due to less loss of photosynthetic area. In addition, a slower thrips buildup would be beneficial for higher returns and the environment by reducing the number of insecticide applications required. It would be interesting to evaluate these entries again because of yearly differences observed. Most of the entries in the study had fewer thrips per plant and lower disease severity and incidence at most of the rating times when compared with the susceptible check 'Rumba'. The aforementioned results showed an improvement for resistance to thrips and IYS after one selection cycle and indicate the potential to make further improvements with additional cycles of selection. For future work, selections were performed on some of the promising entries in 2011 and 2012 to further expand the work on seeing the progress after second generation material. In addition, seeds of NMSU lines that observed to be resistant to IYS disease and thrips in the present and future studies will likely be released to the public and private sector for further testing and incorporation of resistant germplasm in the advanced breeding materials. Overall, a limited amount of progress was observed in some of the selected populations from its original populations.

\section{Literature Cited}

Al-dosari, S.A. 1995. Development of an IPM system for onion thrips (Thrips tabaci Lindeman) as a pest of bulb onions. Colo. State Univ., Fort Collins, CO, PhD Diss., 124 pp.

Bag, S., P. Rogers, R. Watson, and H.R. Pappu. 2009a. First report of natural infection of garlic (Allium sativum) with Iris yellow spot virus in the United States. Plant Dis. 93:839.

Bag, S., J. Singh, R.M. Davis, W. Chounet, and H.R. Pappu. 2009b. Iris yellow spot virus in onion in Nevada and northern California. Plant Dis. 93:674.

Boateng, C.O., H.F. Schwartz, M.J. Havey, and K. Otto. 2014. Evaluation of onion germplasm for resistance to Iris yellow spot (Iris yellow spot virus) and onion thrips, Thrips tabaci. Southwest. Entomol. 39:237-260.

Copeland, R. 1998. Assaying levels of plant virus by ELISA, p. 455-460. In: G.D. Foster and S.C. Taylor (eds.). Methods in molecular biology. Vol. 81: Plant virology protocols: From virus isolation to transgenic resistance. Humana Press, Totowa, NJ.

Cortês, I., I.C. Livieratos, A. Derks, D. Peters, and R. Kormelink. 1998. Molecular and serological characterization of Iris yellow spot virus, a new and distinct tospovirus species. Phytopathology 88:1276-1282.

Coudriet, D.L., A.N. Kishaba, J.D. McCreight, and W.G. Bohn. 1979. Varietal resistance in onions to thrips (Thysanoptera, Thripidae). J. Econ. Entomol. 72:614-615.

Cramer, C.S., S. Bag, H.F. Schwartz, and H.R. Pappu. 2011. Susceptibility of onion relatives (Allium spp.) to Iris yellow spot virus. Plant Dis. 95(10):1319.

Cramer, C.S., N. Kamal, and N. Singh. 2017. Evaluating Iris yellow spot disease incidence and severity in onion germplasm of varying leaf characteristics. HortScience 52:527532.

Cramer, C.S., M. Mohseni-Moghadam, R.J. Creamer, and R.L. Steiner. 2012. Screening winter-sown entries for Iris yellow spot disease susceptibility, p. 80-99. In: S. Walker and C.S. Cramer (eds.) Proc. 2012 Natl. Allium Res. Conf., Las Cruces, NM.

Cramer, C.S., N. Singh, N. Kamal, and H.R. Pappu. 2014. Screening onion plant introduction accessions for tolerance to onion thrips and Iris yellow spot. HortScience 49:1253-1261.

Creamer, R., S. Sanogo, A. Moya, J. Romero, R. Molina-Bravo, and C. Cramer. 2004. Iris yellow spot virus on onion in New Mexico. Plant Dis. 88:1049.

Crowe, F.J. and H.R. Pappu. 2005. Outbreak of Iris yellow spot virus in onion seed crops in central Oregon. Plant Dis. 89:105.

Damon, S.J., R.L. Groves, and M.J. Havey. 2014. Variation for epicuticular waxes on onion foliage and impacts on numbers of onion thrips. J. Amer. Soc. Hort. Sci. 139:495-501.

Diaz-Montano, J., J. Fail, M. Deutschlander, B.A. Nault, and A.M. Shelton. 2012. Characterization of resistance, evaluation of the attractiveness of plant odors, and effect of leaf color on different onion cultivars to onion thrips (Thysanoptera: Thripidae). J. Econ. Entomol. 105:632-641.

Diaz-Montano, J., M. Fuchs, B.A. Nault, J. Fail, and A.M. Shelton. 2011. Onion thrips (Thysanoptera: Thripidae): A global pest of increasing concern in onion. J. Econ. Entomol. 104:1-13

Diaz-Montano, J., M. Fuchs, B.A. Nault, and A.M. Shelton. 2010. Evaluation of onion cultivars for resistance to onion thrips (Thysanoptera: Thripidae) and Iris yellow spot virus. J. Econ. Entomol. 103:925-937.

du Toit, L.J., H.R. Pappu, K.L. Druffel, and G.Q. Pelter. 2004a. Iris yellow spot virus in onion bulb and seed crops in Washington state. Plant Dis. 88:222.

du Toit, L.J., G.Q. Pelter, and H.R. Pappu. 2004b. IYSV challenges to the onion seed industry in Washington, p. 213-217. In: C. Swift (ed.) Proc. 2004 Natl. Allium Res. Conf., Grand Junction, CO.

Gent, D.H., L.J. du Toit, S.F. Fichtner, S.K. Mohan, H.R. Pappu, and H.F. Schwartz. 2006. Iris yellow spot virus: An emerging threat to onion bulb and seed production. Plant Dis. 90:1468-1480.

Gent, D.H., H.F. Schwartz, and R. Khosla. 2004. Distribution and incidence of Iris yellow spot virus in Colorado and its relation to onion plant population and yield. Plant Dis. 88:446-452.

Hall, J.M., S.K. Mohan, E.A. Knott, and J.W. Moyer. 1993. Tospoviruses associated with scape blight of onion (Allium cepa) seed crops in Idaho. Plant Dis. 77:952.

Hoepting, C.A., H.F. Schwartz, and H.R. Pappu. 2007. First report of Iris yellow spot virus on onion in New York. Plant Dis. 91:327.

Jones, H.A., S.F. Bailey, and S.L. Emsweller. 1934. Thrips resistance in onion. Hilgardia 8:215252.

Kamal, N. 2016. Selection progress and cost benefit analysis of Iris yellow spot resistance in onions. New Mexico State Univ., Las Cruces, PhD Diss.

Kritzman, A., M. Lampel, B. Raccah, and A. Gera. 2001. Distribution and transmission of Iris yellow spot virus. Plant Dis. 85:838-842.

Mahaffey, L. 2006. Diversity, seasonal biology, and IPM of onion-infesting thrips in Colorado. Colo. State Univ., Fort Collins, CO, Master's Thesis.

Miller, M.E., R.R. Saldana, M.C. Black, and H.R. Pappu. 2006. First report of Iris yellow spot virus on onion (Allium cepa) in Texas. Plant Dis. 90:1359.

Mohseni-Moghadam, M., C.S. Cramer, R.L. Steiner, and R. Creamer. 2011. Evaluating winter-sown onion entries for Iris yellow spot virus susceptibility. HortScience 46:12241229.

Molenaar, N.D. 1984. Genetics thrips (Thrips tabaci L.) resistance and epicuticular wax characteristics of nonglossy and glossy onions (Allium cepa L.), PhD Diss. Abstr. B (Sciences and Engineering) 45:1075B.

Mullis, S.W., D.B. Langston, Jr., R.D. Gitaitis, J.L. Sherwood, A.C. Csinos, D.G. Riley, A.N. Sparks, R.L. Torrance, and M.J. Cook. 2004. First report of vidalia onion (Allium cepa) naturally infected with Tomato spotted wilt virus and Iris yellow spot virus (Family Bunyaviridae, Genus Tospovirus) in Georgia. Plant Dis. 88:1285.

Multani, P.S., C.S. Cramer, R.L. Steiner, and R. Creamer. 2009. Screening winter-sown onion entries for Iris yellow spot virus tolerance. HortScience 44:627-632.

Nagata, T., A.C.L. Almeida, R. de O. Resende, and A.C. de Ávila. 1999. The identification of the vector species of Iris yellow spot tospovirus occurring on onion in Brazil. Plant Dis. 83:399.

New Mexico Climate Center. 2012. Request Timeseries for Leyendecker II PSRC. 27 Nov. 2012. <https://weather.nmsu.edu/ziamet/request/ station/nmcc-da-5/data/>.

Pappu, H. and M. Matheron. 2008. Characterization of Iris yellow spot virus from onion in Arizona. Plant Health Prog., doi: 10.1094/PHP2008-0711-01-BR.

Poole, G.J., H.R. Pappu, R.M. Davis, and T.A. Turini. 2007. Increasing outbreaks and impact of Iris yellow spot virus in bulb and seed onion crops in the Imperial and Antelope Valleys of California. Plant Health Prog., doi: 10.1094/ PHP-2007-0508-01-BR.

Pozzer, L., I.C. Bezerra, R. Kormelink, M. Prins, D. Peters, R. de O. Resende, and A.C. de Ávila. 1999. Characterization of a tospovirus isolate of Iris yellow spot virus associated with a disease in onion fields in Brazil. Plant Dis. 83:345-350.

Schwartz, H.F., W.M. Brown, Jr., T. Blunt, and D.H. Gent. 2002. Iris yellow spot virus on onion in Colorado. Plant Dis. 86:560.

Schwartz, H.F., D.H. Gent, S.F. Fichtner, R.W. Hammon, and R. Khosla. 2005. Integrated management of Iris yellow spot virus in onion, p. 207-212. In: C. Swift (ed.). Proc. 2004 Natl. Allium Res. Conf., Grand Junction, CO. 
Shock, C.C., E.B.G. Feibert, L.B. Jensen, S.K. Mohan, and L.D. Saunders. 2008. Onion variety response to Iris yellow spot virus. HortTechnology 18:539-544.

Singh, N. 2013. Selection progress for reduced Iris yellow spot symptom expression in onion. New
Mexico State Univ., Las Cruces, NM, Master's Thesis.

Srinivasan, R., S. Sundara, H.R. Pappu, S. Diffie, D.G. Riley, and R.D. Gitaitis. 2012. Transmission of Iris yellow spot virus by Frankliniella fusca and Thrips tabaci
(Thysanoptera: Thripidae). J. Econ. Entomol. 105:40-47.

Walker, S., J. Ashigh, C.S. Cramer, T. Sammis, and B. Lewis. 2009. Bulb onion culture and management for southern New Mexico. New Mexico Coop. Ext. Serv. Circ. 563. 